\title{
SOBRE LA GUERRA Y LA PAZ: \\ EL ACUERDO ENTRE TREMECÉN Y LA CORONA DE ARAGÓN $(1362)^{1}$
}

\author{
MARÍA DOLORES LÓPEZ PÉREZ \\ Universidad de Barcelona
}

\begin{abstract}
SUMARIO
1. Los prolegómenos.- 2. Los requerimientos de Pedro III.- 3. La respuesta zayyaní.- 4 . Las cuestiones pendientes.- 5. ¿Unas conclusiones'?Apéndice documental.
\end{abstract}

\section{LOS PROLEGÓMENOS}

A finales de 1362, hacia el mes de octubre, partía Francesc Sacosta hacia la capital del sultanato abd al-wadí, Tremecén. Su primer destino lo debía constituir alguno de los principales puertos de la corona - seguramente Valencia o Mallorca-, donde la orientación preferente de sus operadores permitía fletar sin dificultad alguna de las embarcaciones que cubrían las rutas magrebíes. Mallorquines y valencianos frecuentaban Honein y

\footnotetext{
'Este trabajo es uno de los resultados del proyecto de investigación La Corona de Aragón y los países islámicos en la Baja Edad Media: el marco político-militar y los intercambios económicos y culturales, dirigido por la Dra. M. Teresa Ferrer Mallol, Investigadora del Consejo Superior de Investigaciones Cientificas, y patrocinado y financiado por la Dirección General de Investigación Científica y Técnica (DGICYT), con referencia PB 94-0123.
}

"Anuario de Estudios Medievales". 29 (1999) 
Mostaganem, antepuertos de la ciudad de Tremecén ${ }^{2}$. O quizás, la importancia del asunto a tratar hubiese requerido la conveniencia de armar una galera que, desde Barcelona, permitiera a Sacosta arribar con rapidez a las costas zayyaníes. Una notificación del gobernador del reino de Mallorca, Bernat de Tous, informando a todos los patrones y cómitres de la naturaleza del viaje de Sacosta nos permite, sin embargo, concretar con precisión el punto de partida: el puerto de Mallorca ${ }^{3}$.

El embajador había recibido instrucciones específicas del monarca: negociar una paz deseada desde hacía años pero que la coyuntura política del momento había vuelto inviable. Para ello, le acompañaba un trujamán, un intérprete, un mercader mallorquín llamado Berenguer Llobet, cuyos negocios debían haberle llevado en numerosas ocasiones a viajar o incluso residir en territorio zayyaní ${ }^{4}$.

\section{LOS REQUERIMIENTOS DE PEDRO III}

La firma de un texto, donde se recogían las cláusulas habituales en este tipo de acuerdos, y unas directrices precisas sobre las concesiones que debía negociar con el sultán abd al-wadí era lo que Sacosta debía procurar obtener de su estancia en la corte de Abu Hammu. La iniciativa, no obstante, parecía haber partido del propio sultán: dos embajadores, Muhammad ibn Idris y Yusuf ibn Abd Allah encabezaban una embajada que arribó a la corte catalanoaragonesa, con una carta de presentación escrita en árabe - "con su carta scripta en arábico e siellada con su siello", dice Pedro el Ceremonioso-, con el objeto de negociar un acuerdo satisfactorio para

'Catalanes, mallorquines y valencianos operaban en los enclaves magrebies con diferente intensidad y con distintas imbricaciones, incluso podríamos establecer hipótesis sobre una probable división tácita de áreas de influencia. Un análisis de esta cuestión puede verse en M.D. LÓPEZ PÉREZ, La Corona de Aragón y el Norte de Africa: las diferentes áreas de intervención mercantil catalano-aragonesa en el Magreb a finales del siglo XIV y principios del XV, "Acta Historica et Archaeologica Mediaevalia", 11-12 (1990-1991), pp.299-323; idem, La Corona de Aragón y el Magreb en el s.XIV (1331-1410), Barcelona: Institución Milá y Fontanals, 1995, pp. 169-267.

${ }^{3}$ Archivo del Reino de Mallorca (ARM), Lletres Comunes (LLC), 26, f. 216 r.-v. (Mallorca. 10. octubre, 1362) $365)$

Archivo del Reino de Mallorca (ARM), Extraordinaris, ff. 7 v. -43 r. (Mallorca. 7 enero, 
ambas partes ${ }^{5}$. En Perpiñán, donde en esos momentos se encontraban la corte, el monarca hace redactar al notario Bertran de Pinós un borrador, pendiente de aprobación por parte del sultán zayyaní, donde se repiten las cláusulas habituales. La seguridad y la libertad de tránsito de personas y bienes, la neutralidad ante posibles enfrentamientos bélicos con terceros y la ayuda y apoyo necesarios frente a posibles enemigos y una duración de cinco años configuran el contenido. Las firmas del arzobispo de Tarragona, Pere, y de los consejeros Bernat de Cabrera, Ramon Alamany de Cervelló, Artal de Foces y Francesc de Cervià, validan el documento que Francesc Sacosta debe presentar al sultán abd al-wadí Abu Hammu II $^{6}$.

Cuestiones paralelas, relacionadas con la signatura de la tregua, debían ser asimismo negociadas por Sacosta. Pedro el Ceremonioso se encarga de destacar la importancia de estos asuntos en la carta de recomendación que, junto con el tratado, entrega a su embajador antes de partir hacia Tremecén?.

Primero, negociar una solución factible del 'asunto Mercer'. Dos años antes, en 1360, la situación interna del sultanato estaba amenazada por la presencia mariní. En la primavera de ese año, el sultán de Marruecos Abu Salim lanza una ofensiva contra Tremecén. La reaparición de una política expansiva mariní hacia el este ${ }^{\mathrm{x}}$ inquieta a Abu Hammu; una inquietud que se vio confirmada tras la entrada de las tropas mariníes en la capital en junio de 1360 , su propia huida y el nombramiento de un califa títere, el zayyaní disidente Abu Zayyan II.

La invasión de sus territorios por los mariníes obliga a Abu Hammu a negociar con el monarca catalanoaragonés el alquiler de cuatro galeras con el objetivo específico de defender las posiciones costeras ${ }^{9}$. La desesperada situación del zayyaní explica la elevada suma que estaba dispuesto a versar por cada una de las galeras: 1.100 doblas mensuales. Pedro III las envió comandadas por Mateu Mercer y, tal y como se había convenido, llegaron a la villa hafsí de Bona, desde la que debían atacar las posiciones de los

\footnotetext{
5Apéndice documental, n" 1 y 5.

'Texto reproducido en el apéndice documental, $n$ " 1 .

${ }^{7}$ Apéndice documental, $n$ "2.

${ }^{8}$ Sobre la expansión mariní hacia el este of. M.D. LóPEz PÉrez, La Corona de Aragón y el Magreb, pp. 56-57, 119-123.

${ }^{9}$ Archivo de la Corona de Aragón (ACA), Cancillería (C), reg.555, f.126 v. (Zaragoza. 1, junio, 1360).
} 
Banu Marín en las costas zayyaníes. Pero aquí el sistema de las alianzas jugó en contra de los intereses catalanoaragoneses: galeras castellanas, aliadas de los mariníes, derrotaron y hundieron las galeras de Mateu Mercer ${ }^{10}$. Una parte de la tripulación fue arrestada y encarcelada, parece ser que con el beneplácito de Abu Hammu, quien en julio de ese mismo año recuperó el trono tras entrar en la capital y expulsar a Abu Zayyan II.

A ello se añadía la falta de satisfacción de la paga del corto período en que las galeras permanecieron al servicio de los abd al-wadíes". El impago y el encarcelamiento de la tripulación incidió con toda seguridad en la ruptura de las negociaciones de una tregua que debía haber sido firmada en $1360^{12}$ y que no se concretó hasta 1362 .

Las instrucciones entregadas a Sacosta no mencionan el pago de las cantidades pendientes, únicamente la liberación de los tripulantes aún encarcelados, así como del resto de cautivos catalanoaragoneses en territorios zayyaníes $^{13}$. Las particulares circunstancias políticas que atravesaba la Corona de Aragón, recordemos que en 1362 se reinician los enfrentamientos con Castilla, hacían necesaria la obtención rápida de un acuerdo de marcado carácter político; un tratado que sellase una alianza activa, de colaboración

\footnotetext{
${ }^{10}$ Este episodio es descrito por Ch.E. Dufourco, Les activités politiques et économiques des catalans en Tunisie et en Algerie oriental de 1262 à 1377, "Boletín de la Real Academia de Buenas Letras", XIX (1946), p.86; idem, Les espagnols et le royaume de Tlemcen aux XIIIè et XIVè siècles, "Boletín de la Real Academia de Buenas Letras", XXI (1948), pp.105-106. F. Almela Vives relata el incidente con los castellanos en el contexto de una reconstrucción de la vida de Mateu Mercer [El almirante Mateo Mercer, Castellón de la Plana: Sociedad Castellonense de Cultura, 1954, pp.41-43].

"ACA, C, reg. 1389, f.29 r.-v. (Barcelona. 5, noviembre, 1361); ibidem, f.30 r. (Valencia. 24, febrero, 1362); ibidem, f.31 r. (Valencia. 18,marzo, 1362); reg. Ch.E. DuFourcQ, Catalogue chronologique et analytique du registre 1389 de la chancellerie de la Couronne d'Aragon intitulé "Guerre Sarracenorum" 1367-1386 (1360-1386), "Miscelánea de Estudios Medievales", II (1974), docs.20, 21 y 23, pp.72-73.

1.'En mayo de 1360 existía una copia de un futuro tratado según se desprende de la dócumentación conservada [ $c f$. M.D. LÓPEZ PÉREZ, La Corona de Aragón y el Magreb. p. 124].

${ }^{13} \mathrm{La}$ diplomacia catalanoaragonesa no había permanecido impasible al problema de los encarcelamientos desde que éstos se produjeron en 1360. Las cartas dirigidas por el rey al propio sultán y al cónsul catalán en Honein evidencian su preocupación por la situación de sus súbditos. La respuesta de Abu Hammu parece haber sido, no obstante, contradictoria. Confirmaba la presencia de algunos de los tripulantes en su reino a sueldo del sultán y diponiendo de una total libertad de movimientos. La falta de credibilidad y la constancia, según afirmaciones del monarca, de la efectiva encarcelación de sus súbditos, ocasiona el envio de un embajador, Joan Ferrer, en un intento de solucionar el conflicto diplomático [ACA, C, reg. 1389, f.29 r.-v. (Barcelona. 5, noviembre, 1361); ibidem, f.30 r. (Valencia. 24, febrero, 1362); ibidem, f.30 v. (Valencia. 24, febrero, 1362); ibidem. f.31 r. (Valencia. 18, marzo, 1362)].
} 
estrecha contra los castellanos, o en su defecto pasiva, al anular cualquier posible intento de pacto y ayuda entre Castilla y Tremecén ${ }^{14}$. La solicitud de una licencia especial de exportación de 1.000 caballos, cueros y cereales, así como la petición expresa de prohibir estas mismas extracciones a los castellanos son una prueba evidente de la necesidad de esta alianza ${ }^{15}$.

\section{LA RESPUESTA ZAYYANí}

¿Accedió Abu Hammu a las peticiones de Pedro III? Seguramente la petición de libre exportación no debió ocasionar problemas importantes a nivel de negociación. La aceptación de las cláusulas estipuladas por el monarca catalanoaragonés no suponían ni una implicación directa del sultán zayyaní en el conflicto con Castilla, ni un desembolso de capital. No obstante, no existe constancia documental de una aprobación.

El 18 de diciembre Abu Hammu ratificaba, en líneas generales, las cláusulas del tratado que había recibido de manos de Francesc Sacosta. El texto del tratado enviado a la corte catalanoaragonesa evidencia la repetición de los términos expresados en los tratados-tipo, sin que la 'cuestión Mercer', aparezca expresada en ningún momento.

Alí al-Qamia fue el emisario encargado de presentar ante Pedro III el acuerdo de paz, escrito en árabe, tal y como había solicitado el monar$\mathrm{Ca}^{16}$; una tregua que, finalmente, fue promulgada el 23 de marzo de 1363 , estableciéndose la vigencia a partir del 1 de enero de ese año ${ }^{17}$.

\footnotetext{
${ }^{14}$ Maniobras políticas similares se entretejieron con la corte de Fez dando como resultado la firma de un tratado, en 1357, al que se uniría Granada y Sicilia; acuerdo que, por otro, lado, al igual que sucede con Tremecén, no deja de ser un instrumento de neutralidad, no de colaboración, ante el desinterés mariní de reiniciar la expansión en la península ibérica [M.D. López Pérez, La Corona de Aragón y el Magreb, pp.96-99].

${ }^{15}$ Apéndice documental, $n^{\circ} 3$. Petición ratificada a través de una carta personal enviada por el monarca a Abu Hammu II [Apéndice documental, $n^{0} 4$ ].

${ }^{16} \mathrm{El}$ texto árabe se conserva en el Archivo de la Corona de Aragón y ha sido publicado en su versión original y la traducción al castellano por $\mathbf{M}$. Alarcón y R. García de Linares [Apéndice documental, $n^{\circ 6}$ ]

${ }^{17}$ Apéndice documental, $n^{107}$
} 


\section{LAS CUESTIONES PENDIENTES}

El asunto Mateu Mercer se configura como la principal cuestión pendiente de resolución tras la firma del acuerdo. Prueba de ello es la renovación de los contactos diplomáticos cuatro años más tarde, en 1366. El embajador en esta ocasión es Guillem Roig.

Roig se enfrentará a una difícil tarea que conjuga reclamaciones monetarias y peticiones de libertad de cautivos. El Ceremonioso entrega en este sentido instrucciones precisas: en primer lugar, reclamar el pago del servicio efectuado por las galeras comandadas por Mateu Mercer seis años antes, siempre a razón de 1.100 doblas mensuales por galera; en segundo lugar, la liberación de los miembros de la tripulación que aún permaneciesen con vida y que, según afirmaba el monarca, estaban siendo retenidos por Abu Hammu; en tercer lugar, la devolución de los presentes que el sultán de Marruecos enviaba a Pedro el Ceremonioso y que habían sido confiscados por el zayyaní tras su entrada en la ciudad de Orán, según había constatado Francesc Sacosta en su viaje como embajador a Tremecén; y en último lugar, Roig debería pedir al sultán que permitiera el regreso a la Corona de Aragón de los hombres de la milicia cristiana que así lo desearan ${ }^{18}$.

¿Resultados? Negativos según se deduce de una nueva embajada encomendada en 1369 a Joan Roig, quien sumó un nuevo fracaso ${ }^{19}$. Nueve años después de la captura seguimos sin tener constancia de la consecución de unos acuerdos satisfactorios para ambas partes. Con toda seguridad la cuestión monetaria continuó siendo un problema irresoluble que con el paso del tiempo quedaría relegado ante la imposibilidad de obtener un acuerdo satisfactorio. ¿Y la tripulación? Quizás en parte consiguió regresar, tal vez el resto engrosó las filas de la milicia cristiana.

\footnotetext{
${ }^{18}$ ACA, C, reg. 1389, ff.66 v.-67 r. (Zaragoza. 13, julio, 1366); publ. parcial, J.M. Ramos Loscertales, El cautiverio en la Corona de Aragón durante los siglos XIII, XIV y XV, Zaragoza, 1915, doc.22, pp.XXXVII-XXXVIII; reg. Ch. E. Dufourcq, Catalogue, doc.96, pp.89-90.

${ }^{19} \mathrm{ACA}, \mathrm{C}$, reg. 1389 , ff.75 v. -76 r. (Barcelona. 25, abril, 1369); reg. Ch. E. Dufourcq, Catalogue, doc. 125, p.97.
} 


\section{5. ¿UNAS CONCLUSIONES?}

Espacio-cojín entre dos potencias - Marruecos y Túnez-, Tremecén se configura a lo largo del XIV como una área de intensa intervención mercantil de los operadores valencianos y mallorquines. Incluso es posible que sus mercados sean más transitados que los de sus vecinos mariníes y hafsíes. Y sin embargo, los contactos diplomáticos son, en cierta medida, eventuales. Territorio intervenido por los marinies durante una gran parte del siglo, únicamente a raíz de las temporales restauraciones se establecen intentos recíprocos - Corona de Aragón/Tremecén- de consolidar unas buenas relaciones políticas que faciliten no tanto los intercambios como la colaboración en política internacional.

Diversas cuestiones quedan planteadas como consecuencia del tratado de 1362-63. En primer lugar, la propia dinámica de las relaciones Corona de Aragón-Tremecén. ¿Por qué se firma un acuerdo en 1362 -recordemos, tras un intento fallido en 1360-? La guerra con Castilla condiciona, sin duda, como ya hemos analizado, la diplomacia catalanoaragonesa con los sultanatos norteafricanos.

Segunda cuestión: el asunto Mercer y sus implicaciones en la política interna magrebí. Nuevamente aparece Castilla. Recordemos que la derrota de la flota comandada por Mercer fue debida a una intervención castellana en apoyo de sus en ocasiones aliados, a veces enemigos, los mariníes. La política internacional se entremezcla en los asuntos magrebíes ¿quizás como muestra de debilidad interna? 


\section{APÉNDICE DOCUMENTAL}

1362, junio, 25. Perpiñán

Tratado concluido en Perpiñán entre Pedro el Ceremonioso y Abu Hammu, sultán de Tremecén, con una duración de 5 años.

ACA, Cancilleria, reg. 1389 , ff. 33 r. -34 r.

Cit.: J. Zurita, Anales de la Corona de Aragón, vol. 4, Zaragoza, CSIC, 1973, p. 438 .

Reg. Ch. E. DufourcQ, Catalogue, doc. 31, pp. 74-75.

Cit. IDEM. Les espagnols et le royaume de Tlemcen, pp. 111-112.

Cit. R. ARIÉ, L'Espagne musulmane au temps des nasrides (1232-1492), Paris, Ed. E. De Boccard, 1973, p. 112.

Cit. A.M. AL-ABBADI, El reino de Granada en la época de Muhammad V, Madrid, Instituto de Estudios Islámicos, 1973, pp. 56-57.

Sepan todos quantos esta carta verán e oyrán como nos, don Pedro, por la gracia de Dios rey d'Aragón, et cetera, considerantes al muy alto e muy noble don Bohamo $^{a}$, príncep de los moros, rey de Tremicé e senyor de los abdauets a nos nuevament haver embiados sus solemnes e grandes mandaderos, yes a saber, Mahomet Abenadriç e Juceff aben Abdella, con su carta scripta en arábico e siellada con su siello grant por requerir nos con grant instancia de su part de patzes e de treguas, segund otras vetzes en el tiempo passado eran acustumbradas ${ }^{b}$ seyer entre nos e los reyes de Trimicé, senyors de los abdaluets en los tiempos passados, segund en la dita carta era muy largament contenido, por esto nos, querientes seguir e tener la costumbra et manera de la nostra casa rayal e de nostros ${ }^{\mathfrak{c}}$ predecessores $^{\text {d }}$ reyes muy altos d'Aragón, los quales acostumbraron siempre, por tirar danyos, malos e periglos temporales e spirituales, dar e atorgar patzes e treugas a todos reyes del mundo, si quiere cristianos, si quiere moros, qui querrán seyer con ellos en buenas e firmas patzes e treugas e querientes complazer a les rogaríes del dito rey e supplicación de los ditos sus mandaderos qui $\mathrm{i}^{\mathrm{e}}$ cun grand instancia las ditas patzes e treugas nos requerían e por part del dito rey nos demandavan et cobdiciantes assimismo redrar e tirar las grandes mortes, danyos, robarias e menoscabos de 
nuestros bassallos, las quales muytas vetzes por occasión de las guerras passan e soffran en lures cuerpos e algos, por tenor de la present pública carta e privilegio nuestro, de grado e de cierta sciencia nostra, por nos e por todos los nuestros succeidores e herederos, vassallos e súbditos fazemos e firmamos buenas e firmas patzes e treugas con vos, muy alto don Abdella Muçe, rey de Tramicé, e con todos vuestros vassallos e súbditos qualesquiere, yes a saber d'esto dia de la present carta se faze en cinco anyos primeros a venideros e seguientes, prometientes nos a vos, dito rey, e a los vuestros vassallos e súbditos, que por nos, ni por alguno de los nuestros súbditos, ni por galeas, naves, ni otros vaxellos nuestros, ni de nuestros súbditos o vassallos, paladinament, ni scondida non vos será fecho, ni buscado en persona, ni en benes vuestros, ni de vuestros vassallos e súbditos mal, ni danyo, ni desonra alguna de fetxo, ni de dicho, ni por otra manera alguna, antes queremos e atorgamos con la present que todos e qualesquiere vassallos e súbditos vostros, con qualesquiera mercadarías, robas, dineros, biandes e todos otros bienes lures, puedan venir, andar, star e recudir en e por todos los regnos, e tierras, e puertos nuestros como vassallos e súbditos de vos, dito alto rey, salvament e quitia e sin todo embargo, assí que en aquellos ditos regnos, ni terras, ni senyorío, ni puertos nuestros, d'achá ne d'allá las mares, los ditos súbditos e vassallos vuestros, ni lures bienes no puedan seyer detenidos, ni embergados en alguna cosa, ni haún pode seyer, ni scayer naufraig alguno por vuestros vassallos dentro los ditos nuestros regnos e tierres, ni mares por fortuna de mar, ni por otra manera alguna de scaycerse podiesse; et más, prometemos a vos, dito rey, e a vuestros súbditos e vassallos, que durante el dito tiempo de cincho anyos de las presentes patzes e treugas nos, ni vassallos nuestros no ajudaremos o seremos en ajuda de rey alguno con al qual vos seades a present, ni d'aquí adelant podades seyer en guerra durante los ditos cinquo anyos, ni a d'aquello daremos favor, consello, ni ajuda contra vos, ni vuestros regnos, ni terras, vassallos e súbditos vuestros, ni los vassallos, ni bienes d'aquellos, antes vos e aquellos súbditos e vassallos vuestros trattaremos e hauremos como amigos con los quales havemos buenas e firmas patzes et treugas et aún aquellos quanto en nuestro senyorío por todo nuestro poder deffendremos de todos vuestros enemigos.

Estas empero patzes e treugas fazemos nos, dito rey, con condición que vos, dito rey de Tramicén, fagades e firmedes por vos e por vuestros súbditos semblantes mismas patzes e treugas de aquestas e ací largament como en esta carta ça contiene, mandantes por esta misma a todos e cada uno governadores, almirantes, capitanes, cossarios e armadores de galeas, de naves e de lenyes, justicias, guardianos de puertos, salmedinas, vegueres, bayles o otros quallesquiere officiales e súbditos nuestros e a los lugarestinientes de los ditos officiales, presentes e esdevenidores, que les presentes patzes e treugas por todo el dito tiempo de cinquo anyos haian por firmas e valederas e contra aquellas no vinguan por alguna razón deiús pena de la ira e indignación nuestra, en testimonio de las quales cosas la 
present carta nuestra mandamos seyer feycha e con seyello de la nuestra magestat seyer segellada, la qual fo fecha en el castiello de Perpenyá, de la tierra de Rosselló, a vint e cinco junyo en el anyo de la nativitat de nuestro Senyor MCCCLXII, e de nuestro regno vient e siet. Visa Rodericus. Rex Petrus.

Signo de nos, don Pedro, por la gracia de Dios rey d'Aragón, et cetera.

Testimonios fueron a aquesto don Pedro, arcebispo de Terragona, cancellero, don Bernaldo de Cabrera, don Ramón Alamany de Cervelló, don Artal de Foces e don Francesc de Cervián, cavalleros e conselleros del dito senyor rey.

Signo de mi, Bertrán de Pinós, secretario del muy alto e muy excellent senyor, mi senyor el rey d'Aragón, e por autoridat d'aquell notario publico por toda la tierra e senyoría suya, qui a las cosas sobraditas present fue e estas scrivir fiz con letras en raso puestas en la linea VI do se dize "poderes" e cerré.

firmavit.

Dominus Rex mandavit Bertrando de Pinos, in cuius posse predictam

Probata.

De tenore predicti instrumenti fuerunt facta duo publica instrumenta quorum alterum remansit penes dominum regem et in archivo regio repositum et alterum fuit missum regi Trimicem predicto per Francesc ça Costa, militem et consiliarium dicti domini regis Aragonum.

(En el margen superior, encabezando el documento, en letra coetánea) Instrumentum pacis inite inter dominum ${ }^{\mathrm{g}}$ Aragonum et regem Trimicen.

\footnotetext{
". Sigue Muce, tachado.- ". Sigue seex, tachado.- ‘. Sigue succehidors, tachado.". predecessores, interlineado.- ". Sigue esto. tachado.- '. dito, interlineado.- ". dominum, interlineado.
}

1362, junio, 30. Perpiñán

Pedro el Ceremonioso se dirige a Abu Hammu, sultán de Tremecén, para notificarle que le envía como embajador a Francesc Sacosta, quien le llevaba el texto del tratado.

ACA, C. reg. 1389, f.34 r.-v.

Reg. Ch.E. DurourcQ. Caralogue, doc. 32, p.75.

Don Pedro, por la gracia de Dios rey d'Aragón, et cetera, al muy alto e muy noble don Boamo ${ }^{a}$, príncep de los moros, rey de Tramicé e senyor de los abdaluets. 
Rey, fazemos-vos saber que nos embiamos al amado consellero nuestro Francesc Çacosta, cavallero, a la vuestra presencia por aduzir a nos la carta de las patzes e treugas nuevament firmadas entre nos e vos scripta en arábico, segund d'aquella que a vos embiamos scripta en letra cristianesca, por que rey muyto vos rogamos que la dita carta nos embiedes por el dito nuestro mandado scripta en arábico segund dito es. Otrosí, rey, vos rogamos que sobre otros afferes, los quales al dito mandadero nuestro vos deve dezir de nuestra part querades creyer al dito mandadero de lo que us dirá de nuestra part. Et aquello complir por obra segund pertenesce a vuestra honra e nos de vos confiamos et hauremos vos que gradecer. Et si algunas cosas vos plazen que fagamos por vos, fazer lo nos saber confiança de complir.

Dada en Perpenyá, a XXX de junyo en el anyo de la nativitat de nuestro Senyor mil CCCLXII. Visa Rodericus.

Dominus rex mandavit Bertrando de Pinos.

Probata

". Sigue Muçe, tachado.- ". segud en el mamuscrito.

[1362, junio, 30. Perpiñán]

Instrucciones entregadas por Pedro el Ceremonioso a Francesc Sacosia, a quien envia en embajada a la corte de Abu Hammu, sultán de Tremecén.

ACA. C. reg. 1389. f.35 r

Reg. Ch.E. Durourco. Catalogue. doc. 34, p.75.

Capítols sobre açò que mossèn Francesc Çacosta ha a fer per lo senyor rey ab lo rey de Tramiçé.

Primerament, feta la salutació acustumada, lo dit mossèn Francesch Çacosta dirà al dit rey que'l senyor rey lo envia a ell per haver les cartes de las paus e trevas ara novellament fermadas entre lo dit senyor e lo dit rey, presents sos missatgers, per què lo dit senyor lo prega que li trameta semblants cartes scrites en aràbich, segons que aquellas del dit senyor son en cristianisch e que faca per manera que sien feytes en la I part del pergamí on no ha res scrit, en la qual és scrita la dita pau fermada per lo dit senyor. Visa Rodericus.

Item, que li plàcia que li vulla liurar tots los cristians sotsmeses del dit senyor, los quals són vuy en sa sanyoría, e los quals romaseren dallà en sa terra 0 encara del rey del Algarp com les galeas d'en Matheu Mercer foren perdudes. 
Item, li do una letra de creença, la qual lo dit senyor tramet al dit rey de Tramicé, per virtut de la qual li dirà com lo dit senyor lo prega, com a bon amich, ab lo qual ha bona amor e bona amistat, que ell li vulla dar treta de $\mathrm{M}$ cavalls per ço com lo rey de Castella, ab lo qual havia pau e treva, li ha trançada la pau ab gran trahició.

Item, lo prech encara que li plàcia donar treta de forment e de cuyram a tots los sotsmeses del dit senyor rey.

Item, que totes les dites coses li plàcia vedar al rey de Castella e a sos sotsmeses per ço com són ${ }^{\mathrm{a}}$ enemichs del dit senyor rey.

Totes aquestes cosas faca son poder lo $\mathrm{dit}^{\mathrm{b}}$ mossèn Francesch que obtenga del dit rey de Tramicén ab totes aquellas millors maneras que porà, les quals obtegudes se'n venga al dit senyor ab los cristians ensemps al pus tost que porà. Visa Rodericus.

Dominus Rex mandavit Bertrando de Pinos.

Probata.

". són, interlineado.- ". Sigue senyor, tachado.

1362, junio, 30. Perpiñán

Pedro el Ceremonioso se dirige a Abu Hammu, sultán de Tremecén, para notificarle que el rey de Castilla acababa de romper la paz que tenía con la Corona de Aragón y pedirle que le enviara 1.000 caballos, grano y cueros, y que prohibiera la exportación de estos productos y ayuda de caballería a sus enemigos castellanos.

ACA, Cancillería, reg. 1389, f.34 v.

Reg. Ch. E. DuFourcQ, Catalogue, doc. 33, p.75.

Don Pedro, et cetera, al muy alto e muyt noble don Bohamo ${ }^{\mathrm{a}}$, príncep de los moros, rey de Tremicé e senyor de los abdaluets.

Rey amigo, por otra carta vos fazemos saber como nos havemos firmades las patzes e buenas treugas por cinco anyos, segund que en ella veredes ésser contenido; assimismo, rey amigo, crehemos que sepades como el rey de Castiella, con el qual crediamos haver buenas e firmas patzes, nos seyendo en el cagrero lugar de nuestros regnos nos ha trabancadas las ditas patzes con grant trayción, porque rey, rogamos vos que ns querades dar e atorgar a nos e a nuestros súbditos sacha de mil cavallos genetos, e de trigo, e de cuyram, et que estas todas cosas querades 
vedar al rey de Castella e a sus súbditos por honra nuestra. Como d'esto faredes a nos grand plazer e nos somos aparellados fazer por vos semblantes cosas e majores en su caso. Et d.esto vos rogamos que querades dar privilegio a nuestro mandadero. Et si algunas cosas, rey, vos plazen que fagamos por vos, ne por vuestra honra, fazet lo nos saber como amigo.

Dada en Perpenyà, a XXX dias de junyo en el anyo de la nativitat de nuestro senyor mil CCCLX dos. Visa rodericus.

Dominus Rex mandavit Bertrando de Pinos.

Probata.

a. Sigue Muce tachado.

1362, junio, 30. Perpiñán

Pedro el Ceremonioso se dirige a Abu Hammu, sultán de Tremecén, para notificarle que habia recibido su carta, a través de sus mensajeros, Mohammed ibn Idris y Jusuf ibn Abdallah, donde le pedía la firma de un tratado de paz. Por este motivo, habia firmado un tratado por cinco años y le pedía que le entregara a su embajador, Francesc Sacosta, un ejemplar del tratado con su firma, y que liberara a todos los súbditos catalano-aragoneses cautivos en sus estados.

ACA, Cancillería, reg. 1389, f. 35 v.

Reg. Ch. E. DufourcQ, Catalogue, doc. 35, p. 75.

Don Pedro, et cetera, al muy alto e muy noble don Boamo ${ }^{a}$, príncep de los moros, rey de Tremicé e senyor de los abdalauetes.

Rey, sabet que vidiemos una carta a nos presentada por Mahomet Abenadriz e Jucef aben Abdalla, mandaderos vuestros, por la qual nos requeriades de pazes e de treguas, a la qual, rey, vos respondemos que nos, catantes la buena e antiga amor e voluntat, la qual de luengo encara fue y es seyda entre la nuestra casa e la vuestra, e queriendo seyer vuestro amigo, segunt fueron los nuestros predecessores de los vuestros, las ditas pazes e treugas por cinco anyos d'aqui adelant primeros a venideros havemos firmadas segunt veredes seyer contenido en nuestra carta seyellada con seyello de la nuestra magestat ${ }^{b} \mathrm{e}$ signada de nuestra mano propia con condición ${ }^{c}$ que vos, rey, fagades aquello mismo. Porque rey, rogamos vos que la carta de las pazes nos enviedes por nuestro mandadero, el qual a vos enviamos por esta razón e la qual fazer scrivir de paraula a paraula tal como aquella 
que nos a vos enbiamos. E aún rogamos vos que con el dito mandadero nuestro nos enviedes todos los nuestros súbditos, qui son en vuestro poder e en vuestro senyorio, francos e quitios e sin todo embargo, como assí se deva fazer e complir entre reyes e amigos entre los quales son buenas pazes e firmas treguas. E si algunes cosas, rey, vos plazen que fagamos por vos, ni por vuestra honra, fazet nos lo saber como amigo.

Dada en Perpinyan, a XXX de junio en el anyo de la nativitat de nuestro senyor MCCCLX dos. Visa Rodericus.

Dominus Rex mandavit Bertrando de Pinos.

Probata.

a. Sigue Muce tachado.- b. Sigue havemus firmadas tachado.- c.- Sigue rey tachado.

1362, diciembre, $18^{1}$

Tratado de paz acordado entre Abu Hammu II de Tremecén y Pedro el Ceremonioso con una duración de cinco años'.

Publ. M. Al.ARCón y R. GARCiA DI: LinARI:S. Los documemos árabes diplomáticos del Archivo de la Corona de Aragón. Madrid. Imp. Estanislao Maestre. 1940. pp. 238-241. Original en árabe publicado en pp. 237-238.

En el nombre de Dios misericordioso y compasivo!

Sea la paz para los siervos suyos, que gozan de su predilección. En Dios ponemos nuestra confianza. ¡Cuán excelente protector es! A Él me encomiendo, el Señor del trono magnífico.

Éste es un tratado de paz, cuyas bases quedan firmemente asentadas, a cuyos resultados y consecuencias hay que atenerse y cuyo autor y contratante ha sido favorecido con el éxito, la buena fortuna y decisiones ventajosas para los súbditos del Estado.

Celebra este convenio, después de invocar la gracia del Señor -iglorificado sea!-, de pedirle que lo guíe por el camino del acierto y de solicitar su ayuda y su divina asistencia, nuestro señor el egregio Sultán, el Monarca de regia estirpe,

'29 de safar de 764.

¿Alarcón y García de Linares establecen que el acuerdo tiene lugar entre Pedro el Ceremonioso y Abu Hammu Musa ibn Abi Yaqub. sultán de Marruecos, si bien Ch. E. Dufourcq puntualiza que el tratado es firmado por el sultán de Tremecén Abu Hammu. 
famoso, ilustre, grande, excelso, ejemplar, de ilustre progenie, de elevada alcurnia, eminentísimo, heroico, sin par, magnánimo, relevante, caballeroso, afortunado, realzado, ejemplar, bienquisto, el Califa justiciero, hombre sin tacha, cumplido caballero, el que cuenta con la ayuda de ejércitos y cabilas, el que tiene bajo el pie a los poderosos, que goza del apoyo de soldados y tribus, el sostenido por Dios, de ánimo resuelto, victorioso, ayudado por Dios, el poderoso Sultán, grande en la generosidad y en la bondad, el portentoso, el excelso, Príncipe de los Creyentes, el que confía sus destinos al Señor del Universo, Abu Hammu Musà, hijo del Príncipe, el egregio, sin par, excelso, de ilustre progenie, de alto rango, relevante, heroico, caballeroso, ejemplar, bienquisto, invencible, de ánimo resuelto, afortunado, realzado, de valor indomable, adornado de nobles prendas y de virtudes en gran número, hombre sin tacha, ilustre, grande, distinguido, ejemplar, de regia estirpe, magnífico, venerado, altamente reputado, el santo Abu Ya'qub, hijo del Príncipe egregio, glorioso, excelentísimo, incontrastable, preeminente, heroico, de valor indomable, de ánimo resuelto, sin par, afortunado, relevante, preeminente, grande, de glorioso renombre, hombre sin tacha, ilustre, realzado, magnífico, venerado, caballeroso, meritísimo, perfectísimo, santo y afortunado, que de Dios goce, Abu Zayd, hijo del Príncipe egregio, excelso, de ilustre progenie, grande, bienquisto, de ánimo resuelto, sin par, ilustrísimo, heroico, invencible, de valor indomable, preeminente, de glorioso renombre, magnífico, hombre sin tacha, venerado, autor de grandes hechos memorables, pródigo en acciones gloriosas, el santo, que de Dios goce, Abu Zakariyya', hijo del Sultán egregio, de alto rango, sin par, ejemplar, realzado, justiciero, meritísimo, bienquisto, heroico, portentoso, de ánimo resuelto, el Monarca sin tacha, cumplido caballero, adornado de grandes prendas personales, abnegado, de valor indomable, renombrado por sus virtudes, el sostenido por Dios, ayudado por Él, ilustre, el eternamente famoso por sus hechos memorables y gloriosas acciones, el magnífico, venerado y santo Abu Yahya Yagmurasan, hijo de Ziyyan - ¡Dios conserve sus vidas, los eleve a la más alta categoría, hágalos poseedores de los más preciados méritos y virtudes, difunda su gloria, haciendo que sean generales las alabanzas que se les tributen, por oriente y occidente, y que no cese su excelsa Majestad de ser especialmente favorecida por la divina solicitud en el más alto grado!-, para concertar la paz y la amistad con el caballeroso, eminentísimo, celebrado, magnífico, venerado, grande, Monarca de glorioso renombre, el Rey de Aragón, Valencia, Mallorca, Cerdeña y Córcega y Conde de Barcelona, el Rosellón y Cerdaña, D.Pedro. ¡Dios le conceda la dicha de merecer su divina complacencia, guíelo por las vías de salvación y hágalo objeto de sus favores por su acatamiento a la divina voluntad!

Llegó a poder de Su Maestad - ¿Dios lo engrandezca con su protección!la carta del Rey D. Pedro y el texto del tratado con el sello en que está representado su signo convencional, el reconocido como originario de él por otros análogos, el 
repetidamente usado en ellos, por mano de su mensajero, el caballeroso, alto dignatario, Fransis Costa, bajo las condiciones siguientes:

Quedará establecida la paz entre ambos por cinco años consecutivos, el primero de los cuales es el setecientos y cuatro, partir del mes de safar del citado año, en el que va fechado el presente documento, y que corresponde al mes cristiano de diciembre $-i$ Dios haga patentes en él la prosperidad y los bienes! -, por todos los dominios de su soberano imperio y los que dependan de su excelsa autoridad, ciudades, campos, comarcas fronterizas, centrales y situadas en los extremos confines- ¡Dios vele por ellas! - y también por todos los pertenecientes al citado Rey D. Pedro, sus ciudades y sus regiones costeras, sean muchas o pocas.

No hostilizará el uno al otro, ni los habitantes de un país a los naturales del otro que por él vayan o vengan, respetándose el estado de paz por los dos países, por las dos religiones y por ambas partes.

Ninguno de los dos países recibirá daño alguno de parte del otro, por ningún concepto, ni será objeto de ninguna agresión, encubierta o manifiestamente. Para estos efectos son igual la tierra y el mar, y tanto en una como en otro se prohibe causar perjuicios, en secreto o declaradamente.

No se cometerá la menor deslealtad, ni será objeto de torcidas interpretaciones el sentido de los extremos que contiene. Mientras dure el plazo del citado convenio no se realizará ninguna incursión, ni será asaltada ninguna caravana. $\mathrm{Si}$ esto se hiciera por parte de los cristianos, quedará su Rey obligado a poner en libertad a los cautivos y a restituir lo que haya sido apresado a los musulmanes por medio del saqueo y la rapiña, o bien a indemnizar su valor, si las cosas robadas no apareciesen y faltaran al buscarlas. Y otro tanto se hará cuando se trate de presa de hombres, u otras cosas, hecha furtivamente.

Y nuestro soberano el Sultán - ¡Dios lo engrandezca con su protección!se obliga a lo mismo en forma análoga y a corresponder lealmente al fiel cumplimiento de lo dicho, después que el asunto sea notoriamente conocido y se sepa de dónde ha procedido el daño y quién ha sido el causante de la deslealtad o de la maldad.

Todo cuanto esté sometido a esta excelsa autoridad, o se halle bajo la obediencia de este soberano imperio, después de concertarse este bien pensado convenio, queda comprendido en el acuerdo y en la paz y sometido a sus estipulaciones.

A los negociantes de unos de los dos países que lleguen al otro con sus mercaderías, sólo se les cobrará la décima y los impuestos fiscales ya conocidos, que gravan sus mercancías, sin añadir a ello cosa alguna. Mientras se hallen establecidos, si residen en las ciudades, o vayan de camino, por tierra o por mar, cuando lleguen, o se marchen, serán tratados con el más completo respeto y con toda clase de consideraciones por parte de todos. 
Si embarranca algún navío perteneciente a negociantes que han salido de este país, o que se dirigen desde el suyo a cualquiera de los puertos de nuestro Soberano - ¡Dios lo engrandezca con su protección! - o de los pertenecientes a su propio país, será restituido a sus dueños cuanto hubiera en dicha embarcación, y nadie podrá hacer nada que vaya contra ellos, ni ponerles obstáculos, sea como fuere, ni a ellos ni a la nave, sino que se les dejará hacer lo que tengan por conveniente con sus enseres, sus dineros, su embarcación y con todas sus mercancías, en todos los casos, si Dios quiere.

Nuestro soberano el Monarca, el Sultán Abu Hamu - ¡Dios lo engrandezca con su protección!-, se obliga a cumplir estas condiciones, e inspira en ellas las estipulaciones y cláusulas, para dejar ajustado entre ambos el presente convenio, objeto de las precedentes conversaciones, comprometiéndose a su estricto cumplimiento en la forma que determina cada uno de los extremos contenidos en el texto.

Da testimonio, por nuestro señor el Sultán Abu Hamu $-i$ Dios realce su dignidad y preste su apoyo a sus banderas! - , de todo cuanto en el documento va consignado de su parte, aquel cuyo testimonio para con su honorable persona ha reclamado el Sultán - isu ser se halla rodeado de perfecciones y la fortuna es inseparable compañera de sus designios y de los medios empleados para lograrlos!-, y se halla en la plena posesión de las condiciones exigidas para dar testimonio.

Esto ha tenido lugar el día veintinueve de safar del año setecientos sesenta y cuatro, que corresponde al dieciocho del mes de diciembre.

Añadido entre líneas: "Por mano de su mensajero Fransis Costa". Vale.

$\mathrm{Y}$ bajo los expresados testimonios se comprende también que siempre que una embarcación perteneciente a cualquiera de los dos países que vaya hacia el otro en demanda de su puerto, busque refugio en él contra algún adversario que le persiga en el mar, con propósito de atacarla y causarles daño, las gentes del puerto donde se refugie están obligadas a prestarle auxilio, evitando que se le cause ningún daño, librándola de caer en manos del enemigo, y defendiéndola hasta donde les sea posible, con todo el esfuerzo de que sean capaces, si Dios quiere. Fecha ut supra.

De todo lo cual da fe: Muhammad, hijo de Ahmad, hijo de Ali, y Abd alRahman, hijo de Ali. ¡Dios, con su misericordia, los trate benignamente! Da fe: Muhammad, hijo de Yusuf, hijo de Muhammad al-Qaysi. Da fe: Muhammad, hijo de Ali, hijo de Ahmad al-Utbi.

Sa'id.

Me consta que goza de plena capacidad: Ahmad, hijo de al-Hasan, hijo de 
1363, marzo, 23. Monzón

Ratificación por parte de Pedro el Ceremonioso del tratado concluido con el sultán de Tremecén Abu Hammu, después de haber recibido el texto árabe que le traía Ali al-Qamia.

ACA, Cancillería, reg. 1389, f.43 r.-v.

Reg. Ch. E. DurourCQ, Catalogue, doc. 48, p.78.

Sepan todos quantos esta carta verán e oyrán como nos, don Pedro, por la gracia de Dios rey d'Aragón, et cetera, considerantes vos, muy alto e muy noble don Bahoma, príncep de los moros, rey de Tremiçén, senyor de los abdaluets, a nos nuevament haver embiado Ali Alcamia, hombre vuestro, con vuestra carta de paz entre nos e vos feyta, scripta en erábico e signada de vuestro senyal e de mano de testimonios e del alcadí, por esto vos, querientes firmar con carta nuestra paz e amistat con vos, dito rey, porque entre nos e vos e nuestros súbditos e los vuestros que haia concordia et buena amor e sean tirades muertas e robarias que se seguian entre los nuestros súbditos e los vuestros, por tenor de la present pública carta, de grado e de cierta sciencia nuestra, por nos e por todos los nuestros vassallos e súbditos, fazemos e firmamos buenas e firmas pazes e treugas con vos, dito rey, e con todos vuestros vassallos e súbditos qualesquiere vos saber del primero dia de janero más cerca passado en cinco anyos primeros a vanideros e seguientes, prometientes a vos, dito rey, e a los vuestros vassallos e súbditos, que por nos, ni por alguno de nuestros súbditos, ni por galeas, naves, ni otros vaxellos nuestros, ni de nostros súbditos et vassallos, paladinament, ni scondida, non vos será fetcho, ni buscado en persona, ni bienes, de vos, ni de vuestros' vassallos e súbditos, mal, ni danyo, ni desonra alguna de feyto, ni de dito, ni por otra manera alguna, antes queremos e atorgamos con la present que todos e qualesquiere vassallos e súbditos vuestros, con qualesquiere mercaderias, ruepas, dineros, biandas e todos otros bienes lures puedan venir, endar, star e recudir e por todos los regnos e tierras e puertos nuestros salvament e quitia e sin todo embargo, assí que en aquellos ditos regnos e tierras, ni senyoria, ni puertos nuestros, de ca e d'ellá les mares, los ditos súbditos e vessallos vuestros, ni lures bienes non puedan seyer detenidos, ni enbergados en alguna cosa, ni ahún pueda seyer, ni scaher naufraig alguno por vuestros vassallos dentro los ditos nuestros regnos e tierras, ni mares por fortuna de mar, ni por otra manera alguna que scayer se podiesse. Et más, prometiemos a vos, dito rey, e a vuestros súbditos e vassallos, que durant el dito tiempo de cinco anyos de las presents patzes e trieugas, no ajudaremos o seremos en ajuda de rey alguno con el qual vos seades agora, ni d'aqui adelant podades seyer en guerra durant los 
ditos cinco anyos, ni a d'aquell daremos favor, consello, ni ajuda contra vos, ni vuestros regnos, ni tierras, vassallos e súbditos vuestros, ni contra los vassallos, ni bienes de aquellas, antes vos e aquellos súbditos e vassallos vuestros tractaremos e hauremos como amigos con los quales havemos buenas e firmas patzes e trieugas, a ahún aquellos quanto en nuestro senyoria por todo nuestro poder deffendremos de todos vuestros enemigos. Mandantes por esta misma carta a todos e cadaunos governadores, admirantes, capitanes, corsarios e armadores de galeas, de naves e de lenyos, e guardianos de puertos, e qualesquiere otros officiales e súbditos nuestros presentes e qui por tiempo serán, que las ditas pazes e treugas por todo el dito tiempo de cinco anyos haian firmas e valideras et contra aquellas no binguen por alguna razón deius pena de la ira e indignación nuestra, en testimonio de la qual cosa la present carta nuestra mandamos seyer feyta e signada de nuestra mano e con signo de nuestro secretario.

Feta fue en el castiello de Muntçó, a XXII dias de março en el anyo de la nativitat de nuestro senyor MCCCLXIII et de nuestro regno XXVIII.

Signo de nos don Pedro, et cetera, qui esto otorgamos e firmamos e mandamos aquí poner el seyello pendient de la nostra magestat. Rex Petrus.

Testimonios fueron d'esto el noble don Artal de Forzes, camarlengo de la alta senyora dona Elionor, reina d'Aragón, muller del dito senyor rey, e don Pero Boyl, bayle general de Valencia, e don Ramón de Pagera, de la dita senyora reyna cavalleros, conselleros del dito senyor rey.

Dominus Rex mandavit mihi Jacobo Conesa.

(En el margen superior, encabezando el documento, en letra coetánea) Instrumentum pacis.

a.- Sigue q tachado.- b. Sigue bienes tachado.

\section{RÉSUMÉ}

En 1362 Abu Hammu II de Tlemcen et le roi catalanoaragonais Pierre III signent un traité qui aura une duration de cinq ans. Les ambassades, les negotiations entre les deux souverains, les demandes de Pierre, les concessions d'Abu Hammu, les pourquois de ce signature, tout ces questions ont été objet d'analyse.

\section{SUMMARY}

In 1362 Abu Hammu II and Peter III signed a treaty for five years. The negotiations between the two sovereigns, Peter's demands, Abu Hammu's concessions, the reasons for this agreement, all these questions have been discussed in the paper. 